\title{
COMPRESSION STRENGTH OF CARBON FIBER LAMINATES CONTAINING FLAWS WITH FIBER WAVINESS
}

\author{
Darrell P. Avery, Daniel D. Samborsky \\ John F. Mandell, and Douglas S. Cairns \\ Montan a State University \\ Bozeman, Montana, 59717
}

\begin{abstract}
Recent studies of carbon fiber and carbon/glass hybrid laminates have reported compression strengths and failure strains which are borderline for wind turbine blade designs, depending upon the reinforcement architecture, matrix resin, and environment. Compressive strength is known to be sensitive to the straightness of the fibers, with even relatively small degrees of waviness or misalignment causing significant decreases in compression properties. The effects of fiber waviness, induced by infusion processes and inherent in fabric architectures, on compressive strength, have been investigated. Structural details such as ply drops and ply joints can cause significant levels of fiber misalignment, depending on parameters such as ply thickness, fraction of plies dropped, ply drop location, ply joint gap, and mold geometry and pressure. These parameters have been varied in the study reported in this paper, with compressive properties determined in each case. The results show that prepreg laminates containing ply drops and joints can provide adequate compressive strength, but that severe knockdowns can occur for geometries where large misalignments are induced.
\end{abstract}

\section{INTRODUCTION}

Fiber misorientation due to ply waviness has been the subject of recent studies of blade materials [1-5] and earlier studies of aerospace prepreg laminates [5-9]. Waviness is expected to reduce compressive strength due to two factors: (1) the fibers may be put into a geometry which exacerbates the basic fiber, strand, or layer buckling mode of failure (Figure 1), and (2) the waviness shifts the fiber orientation off the axis of the ply longitudinal direction, producing matrix dominated failures for plies nominally orientated in the primary

This research was supported by Sandia National Laboratories under subcontract BC7159. load direction $\left(0^{\circ}\right)$ (Figure 2). The second factor may also affect tensile strength in severe cases $[4,5]$.

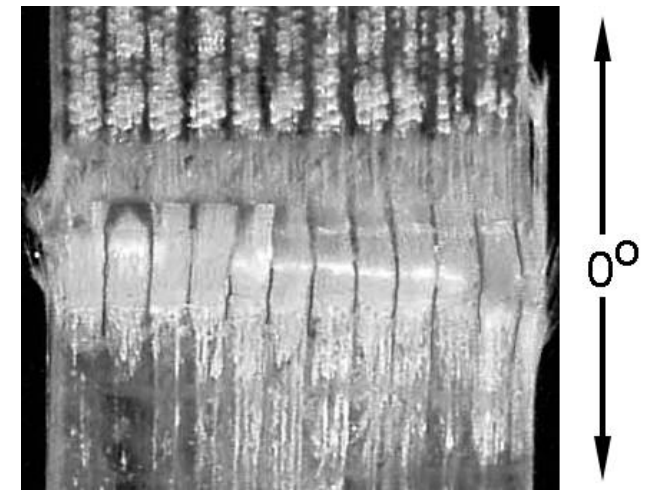

Figure 1. Static Compression Failure Mode for a Typical $[0 / \pm 45 / 0]_{S}$ E-glass Laminate Containing D155 Unidirectional Fabric for the $0^{\circ}$ Plies [3].

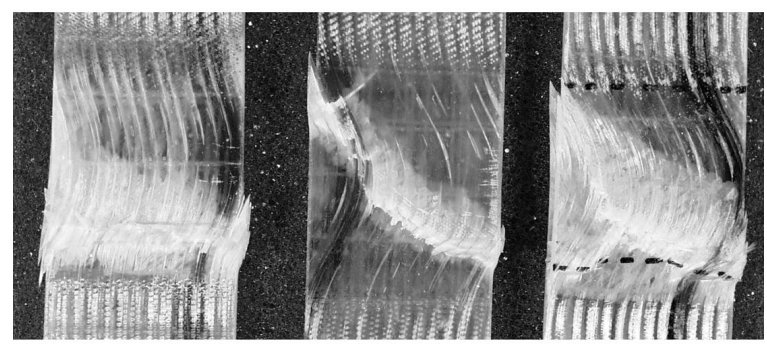

Figure 2. Compression Failures for Glass Fiber Laminates Containing Induced In-Plane Waviness [3, 4].

Compared with typical aerospace prepreg laminates, blade prepregs are thicker, and blade fabrics tend to be both thicker and more heterogeneous, with strands of fiber either woven (usually over a small strand) or stitched together (Figure 3). Wet processing methods such as hand lay-up and variants of resin transfer molding (RTM) can induce severe waviness under some conditions. Severe inplane waviness in a large-tow carbon fiber stitched fabric induced during RTM processing is shown in Figure 4. This is an example of extreme waviness unintentionally introduced during a resin infusion process. Waviness of 
the severity in Figure 4 would be expected to reduce strength properties by a factor of at least two to three relative to a laminate with straight $0^{\circ}$ fibers [3, 4]; less severe waviness as in woven fabrics can also cause serious reductions in strength properties. Misorientation is also produced in otherwise straight-fiber laminates, such as those made from prepreg, at details such as ply-drops [3].

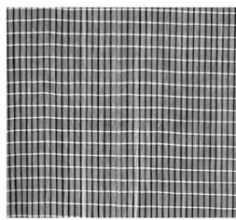

D155

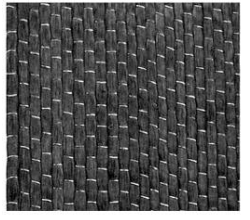

Zoltek UNI25

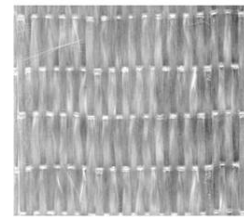
A130

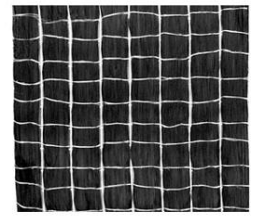

Toray ACM-13-2

$\overline{1 \mathrm{~cm}}$

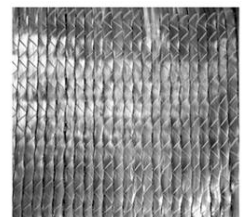
$42024 \mathrm{~L} / \mathrm{M} 50$

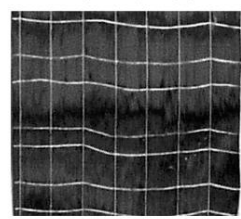

Fortafil 652
Figure 3. Glass (top) and Carbon Fabrics Used in This Study.

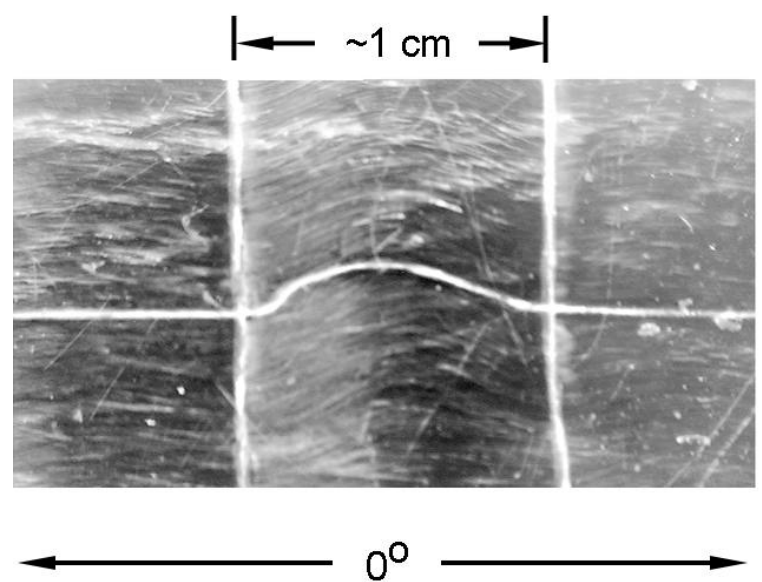

Figure 4. In-Plane $\mathrm{W}$ aviness in a Single-Ply Laminate of Fortafil 652 Carbon Fiber/Epoxy Processed by RTM.

Recent interest in blade materials has shown a significant shift toward carbon fiber and hybrids. Laminates with carbon fibers as the main, $0^{\circ}$, reinforcement are likely to be limited by their compressive properties [2-4]. Carbon laminates constructed from relatively low-cost forms of carbon fiber show compressive ultimate strains in the 1.0 to $1.2 \%$ range when the fibers are nominally straight [3, 4] (there is always some fiber misalignment within individual tows, which may be greater for larger tows [11]). Laminates fabricated by infusion methods, using stitched or woven carbon fabrics, tend to have ultimate compressive strains in the 0.6 to $0.8 \%$ range, which, with statistical treatment and safety factors, could limit blade designs [3].

The work presented in this paper explorers the effects of fiber misalignment in carbon based laminates and hybrids, for cases such as fabrics with inherent waviness and prepreg with ply drops, where moderate levels of misalignment are difficult to avoid. Results are compared with those for glass fiber composites. Since most blades are relatively thick, the ply-drop study includes testing of specimens up to $1 \mathrm{~cm}$ thick, where realistic fractions of $0^{\circ}$ plies can be dropped, producing thickness taper angles which should be representative of blade applications. Testing of thick specimens required significant modification to the usual test methods, and is an ongoing area of concern, as it is with aerospace applications [12].

\section{EXPERIMENTAL METHODS}

\section{Materials}

The $0^{\circ}$ (load direction) reinforcing fabrics used with resin transfer molding (RTM) are shown in Figure 3. Of the E-glass fabrics, stitched weft unidirectional fabric D155 has very straight strands with high strand integrity and is used as a control (despite being of limited practical interest, since it is available only as a weft unidirectional, with fibers orientated perpendicular to the main fabric roll direction). The A130 fabric is representative of a family of warp unidirectional fabrics with similar strands to D155, but woven over a small thermoplastic coated strand. The Ahlstrom 42024L/M50 is a warp unidirectional with the large strands stitched to a light random mat, typical of a number of similar fabrics. Glass fabric is also used for the $\pm 45^{\circ}$ layers with RTM laminates, where present; stitched DB 120 is used in most cases.

The carbon fiber materials (Figure 3) have been limited to evolving large tow materials because of their potentially lower cost. The baseline straight-fiber materials here are prepreg (SP Systems SE84LV/SC300C/300/400/37\% with Toray 300S fibers and SE84LV/HSC/450/400/37\% with Toray T600 fibers). The fabrics used in the RTM laminates are Toray ACM13-2 and Fortafil 652. They are warp unidirectional fabrics with relatively loose construction with some inherent waviness evident. The Toray fabric is stitched and the Fortafil 652 has a bead bonded to the surface of 
the fabric as opposed to stitching. The woven fabric is Zoltek UNI25 (XP33FBUD25), which is tighter and more handleable than the other two fabrics. Laminates with $0^{\circ}$ carbon layers were either unidirectional, combined with dry DB $120 \pm 45^{\circ}$ glass layers, or with $\pm 45^{\circ}$ glass prepreg (Hexcel M9.6/35\%/BB600/G).

Except for prepreg, resins were low viscosity, room temperature infusion resins: ortho polyester (CoRezyn 63AX-051) with 1.5 to $2.0 \%$ by volume Lupersol DDM9, vinyl ester (Derakane $411 \mathrm{C} 50$ or 8084 ) cured with $1.5 \%$ Trigonox 239A, or epoxy (SP Systems Prime 20 with standard hardener).

The hand lay-up and RTM laminates were cured at room temperature and post cured at $65^{\circ} \mathrm{C}$ for 3 hours. The prepreg was cured for 2 hours at $100^{\circ} \mathrm{C}$ in a vacuum bag setup with a vacuum of $75 \mathrm{kPa}$; some cases used additional over pressure as noted. Fiber contents and other details are given with the results.

\section{Test Methods}

Compression tests of RTM laminates and thin $(<6 \mathrm{~mm})$ carbon prepreg laminates used $25 \mathrm{~mm}$ wide rectangular specimens having a gage length of $13 \mathrm{~mm}$, with no lateral constraint on the gage section and no end-loading. Specimens were held in hydraulic grips with special antirotation and anti-deflection restraints described in Reference 2. These were needed for the Model 8501 Instron servohydraulic machine which has hydrostatic bearings and a $6 \mathrm{~cm}$ diameter actuator. Compression tests are designed and validated for materials based failure without elastic buckling. A major issue is whether to provide lateral constraint against out-of-plane movement, such as local strand buckling on surfaces. These tests did not use such constraint, to be representative of most blade service loading conditions.

The displacement rate used in compression tests was relatively fast, $13 \mathrm{~mm} / \mathrm{s}$, to be consistent with fatigue loading rates, except for thick prepreg specimens, which were run at either $13 \mathrm{~mm} / \mathrm{s}$ or $0.25 \mathrm{~mm} / \mathrm{s}$ as noted in the results. It should be noted that the compression strength varies significantly with loading rate for these materials, so that lower rates would provide lower strengths than reported here [2].

The thick prepreg laminates (up to $10 \mathrm{~mm}$ thick) were compression tested with longer, tabbed specimens with end loading and face loading provided by the hydraulic grips. Both thick and thin non-symmetric specimens containing thickness tapering at the ply drops were bonded back-to-back with Hysol 9309.2 NA epoxy, to provide a symmetric specimen to avoid out-of-plane bending. A schematic of a typical ply-drop specimen is shown in Figure 5, and a photograph of a specimen is shown in Figure 6. Selected specimens were strain-gaged with back-to-back gages on each surface, to detect out-ofplane bending. Thick materials were tested in a $250 \mathrm{kN}$ MTS 880 servohydraulic testing machine. This machine has a $10 \mathrm{~cm}$ diameter actuator with a $28 \mathrm{~cm}$ long travel utilizing labyrinth bearings. This provides support which resists lateral movement, and additional restraints were not required.

The specimen in Figure 5 is tested in the back-to-back, doubled geometry to provide symmetry and avoid bending. In practice, in a blade, the tapering areas are not symmetric and this raises an issue of whether the test is representative. The use of symmetric specimens is intended to represent the constraint provided by the blade cross-sectional geometry, which, it is expected, will constrain any bending due to nonsymmetries. It should be noted that materials containing $\pm 45^{\circ}$ glass plies on the surface, with $0^{\circ}$ carbon plies on the interior, may sometimes fail slightly prematurely due to damage in the glass layers, reducing the failure strains relative to unidirectional carbon. This issue is currently under investigation.

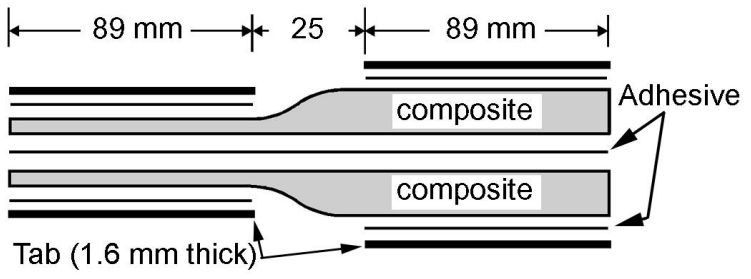

Figure 5. Schematic of Back-to-Back Test Coupon Construction.

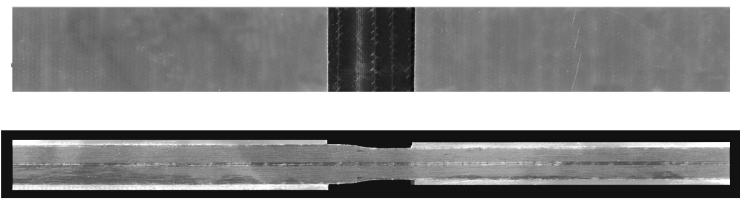

Figure 6 - Photo of untested adhesively bonded back-toback coupon with double ply drops on each side.

\section{RESULTS AND DISCUSSION}

\section{Fabric Waviness in RTM Laminates}

Through-thickness waviness tends to exacerbate the 
fiber or strand buckling compression failure mode of most composites, evident for the typical straight fiber E-glass system using D155 fabric, shown in Figure 1. Even relatively low wave severities, such as those which occur with the A130 fabric in Figure 3, can significantly reduce the compressive strength by predisposing the fabric to the buckling geometry.

The compressive strengths and strains to failure for glass and carbon laminates constructed from several types of fabric are listed in Table 1. The waviness inherent in the A130 glass fabric (Figure 3) at a fiber volume fraction of 43\% (Material DD12 in the DOE/MSU Database [1]), the ply thickness divided by the weave spacing is about $0.04[3,4]$. Comparing this laminate, DD12, with a similar laminate made with a straight-fiber D155 glass fabric, DD8, the compressive ultimate strain drops from the baseline $2.1 \%$ to $1.1 \%$. This nearly $50 \%$ reduction in compressive strength and strain to failure is caused by a wave having an amplitude of about one ply-thickness, which would also be expected around flaws and structural details like ply drops.

Other glass fabrics containing inherent waviness show similarly reduced compressive strength. The traditional woven roving laminate (ROV2) shows a compressive failure strain similar to the woven unidirectional fabrics, about $1.1 \%$. A material form which contains rovings like the D155 fabric, but stitched to a thin mat to provide a nearly unidirectional warp fabric is the Ahlstrom 42024/M50 in Figure 3. However, close inspection of the strands shows significant waviness around the stitches. The compressive ultimate strains for laminates using this fabric, DD27A and DD27B, are also well below the corresponding values for the D155 fabric laminates, DD5P and DD8, at corresponding fiber contents.

Laminates with $0^{\circ}$ layers composed of large-tow carbon fibers show similar effects, but at significantly higher compressive strengths and lower ultimate compressive strains. The latter property is of particular concern in wind turbine blades. Laminates with large-tow carbon fabricated using prepreg contain relatively straight fibers. The ultimate compressive strains for these materials in Table 1 are in the 1.0 to $1.2 \%$ range, which, as expected, is at the low end of data for aerospace carbon fiber prepreg materials which have smaller tow sizes. Test methods with lateral constraints might give higher values, but they suppress the natural failure mode of delaminating/ply buckling normal to the free surface indicated in Figure 1 for a glass fabric and Figure 7 for thick carbon prepreg specimens discussed later. The carbon prepreg ultimate compressive strain values are in the same range as those for woven unidirectional glass laminates such as DD11 - 13 in Table 1, or stitched fabrics like Ahlstrom 42024L/M50, which are typical current blade fabrics.

When the carbon fabrics in Figure 3 are processed by RTM into carbon laminates or hybrid laminates with glass $\pm 45^{\circ}$ layers, materials CGD4, CGD4E and UNI25 in Table 1 , the compressive strains are significantly below $1 \%$, down to the $0.6 \%$ range for the woven UNI25 material with a vinyl ester resin. Epoxy resins produce significantly higher compressive failure strains for the two carbon fabrics in Table 1, which were tested with both resins. Compressive strains are further reduced in fatigue $[3,4]$. The low compressive strains for some cases may limit blade designs using carbon fiber.

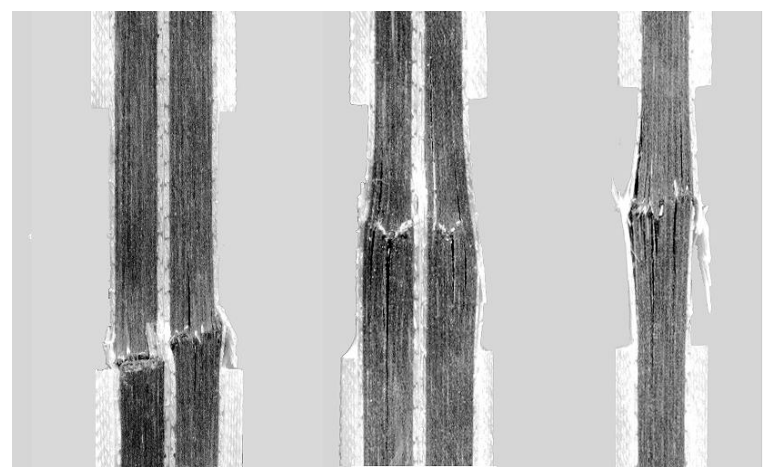

Figure 7. Photo of compressive failures; (left to right) control case, ply drop case and ply joint.

\section{Flaws and Ply Drops in Thin Laminates}

Factors such as ply drops, inclusions between plies, and complex substructure geometries can introduce local through-thickness ply misorientation into laminates. Figure 8 and Table 2 illustrate typical geometries. (As noted earlier, the non-symmetrical geometries (ply drops, ply joints) were compression tested in a symmetrical geometry by bonding two specimens back-to-back on the flat sides to avoid bending and elastic buckling, Figure 5.) The $90^{\circ}$ material inclusion is intended to represent a resinrich area or a loose strand, etc. The reductions in compression ultimate strain correlate with the maximum ply or strand misorientation angle, as expected from literature studies [6]. The reduction in strength and ultimate strain are expected to be less severe for thicker laminates if a lower fraction of plies contain misalignment; this is explored in the next section. Also, distortions like the Figure 8 case (6), a double ply joint with a $6 \mathrm{~mm}$ gap and higher processing pressure, might be reduced for thicker laminates. 
The glass laminates based on straight-strand stitched D155- $0^{\circ}$ fabric show moderate strain reduction $(2.4$ to $1.7 \%$ ) for the double ply drop case, and a similar reduction for the $90^{\circ}$ material inclusion, both of which produce an $8^{\circ}$ misorientation of adjacent $0^{\circ}$ strands. The glass laminates based on the woven A130- $0^{\circ}$ fabric show less reduction in strain relative to the control value using this fabric (1.6 to $1.3 \%$ ), despite a slightly higher misalignment angle of $10^{\circ}$. The inherent waviness in the woven fabric is nearly as bad as that near the inclusion, and the already low ultimate compressive strain is not further reduced to the extent that it is with the straight fiber D155 fabric. Despite this, the straight fiber case still provides higher strain to failure with the inclusion present (1.7 versus $1.3 \%)$.

Knockdown factors in fatigue for the glass laminates are similar to static factors for the $90^{\circ}$ inclusion. However, earlier results [2] showed that the double ply drop produces a much greater knockdown, about a factor of four, in compression fatigue, as delamination grows suddenly and catastrophically from the ply drop area. Fatigue effects are not yet available for the materials reported in this paper.

The prepreg based carbon fiber laminates and carbon/glass hybrids in Table 2 show differing effects at ply joints and ply drops. The most severe reduction in compressive strain capacity occurred with case 6 , the double ply joint, where higher molding over-pressure produced a more severe misalignment (Figure 7, (6)). Here, the compressive ultimate strain value was reduced to only about a third of the control value. Ply drops with less severe geometries still showed reduced compressive ultimate strains to about $60 \%$ of the control range.

Table 1. Static Compressive Strength of Laminates Using Commercial Fabrics (Figure 3) which Contain Varying Amounts of Waviness in $0^{\circ}$ layers (all non $-0^{\circ}$ layers are $\pm 45^{\circ}$ DB 120 glass fabric or Hexcel M9.6/35\%/B B600/G glass/epoxy prepreg) [3].

\begin{tabular}{|c|c|c|c|c|c|c|c|}
\hline $\begin{array}{c}\text { Database } \\
\text { Designation }\end{array}$ & $0^{\mathrm{O}}$ Layers & $\% 0^{\circ}$ & $\begin{array}{l}\mathrm{V}_{\mathrm{F}}, \\
\%\end{array}$ & Resin & $\begin{array}{l}\text { Compressive } \\
\text { Strength, } \mathrm{MPa}\end{array}$ & $\begin{array}{c}\text { Compressive } \\
\text { Strain to } \\
\text { Failure, \% }\end{array}$ & Remarks \\
\hline \multicolumn{8}{|c|}{ Glass Fibers } \\
\hline DD5P & D155 & 72 & 37 & \multirow{8}{*}{ Polyester } & 574 & 2.4 & \multirow{2}{*}{$\begin{array}{l}\text { stitched straight } \\
\text { strands }\end{array}$} \\
\hline DD8 & D155 & 72 & 44 & & 582 & 2.1 & \\
\hline DD11 & A130 & 68 & 30 & & 319 & 1.6 & \multirow{3}{*}{ woven strands } \\
\hline DD12 & A130 & 68 & 43 & & 302 & 1.1 & \\
\hline DD13 & A130 & 68 & 46 & & 314 & 1.1 & \\
\hline ROV2 & $\begin{array}{c}--- \\
-1\end{array}$ & 50 & 35 & & 362 & 1.1 & woven roving \\
\hline DD27A & Ahlstrom & 76 & 32 & & 381 & 1.9 & \multirow{2}{*}{$\begin{array}{l}\text { stitched to mat, } \\
\text { wavy strands }\end{array}$} \\
\hline DD27B & Ahlstrom & 76 & 42 & & 321 & 1.2 & \\
\hline \multicolumn{8}{|c|}{ Carbon Fibers and Hybrids } \\
\hline CGD4 & ACM-13-2 & 76 & 51 & Vinyl ester & 588 & 0.71 & \multirow{2}{*}{$\begin{array}{c}\text { carbon, stitched } \\
\text { fabrics, } \\
\text { low waviness }\end{array}$} \\
\hline CGD4E & ACM-13-2 & 76 & 51 & Epoxy & 684 & 0.81 & \\
\hline UNI25A & \multirow{2}{*}{ UNI25 } & 100 & 45 & Vinyl ester & 535 & 0.61 & \multirow{2}{*}{$\begin{array}{c}\text { woven large tow } \\
\text { carbon }\end{array}$} \\
\hline UNI25B & & 90 & 38 & Epoxy & 630 & 0.78 & \\
\hline CGD5E & Fortafil 652 & 71 & 35 & Epoxy & 565 & 1.15 & \multirow{2}{*}{ bonded carbon } \\
\hline CGD5E2 & Fortafil 652 & 71 & 51 & Epoxy & 546 & 0.73 & \\
\hline CGB4 & se84lv/hsc & 72 & 43 & Epoxy & 828 & 1.0 & prepreg \\
\hline CGB5 & se $841 v / s c 300 \mathrm{c}$ & 63 & 49 & Epoxy & 831 & 1.2 & prepreg \\
\hline CGB6 & se84lv/hsc & 80 & 65 & Epoxy & 1027 & 1.0 & prepreg / glass 45's \\
\hline $\begin{array}{l}\text { SE84LV/ } \\
\text { SC300C }\end{array}$ & Same as above & 100 & 55 & Epoxy & 1310 & 1.05 & $0_{5}$, prepreg \\
\hline
\end{tabular}


Table 2. Effects of Through-Thickness Flaws and Ply Drops on Compressive Strain to Failure (CSF) for Thin Laminates [3].

\begin{tabular}{|c|c|c|c|c|c|c|c|}
\hline Material and Detail & $\begin{array}{c}\text { Edge View } \\
\text { Sketch }\end{array}$ & $\begin{array}{l}\text { Control } \\
(\text { No Flaw) } \\
\operatorname{CSF}^{1}(\%)\end{array}$ & $\begin{array}{c}V_{F} \\
(\%)\end{array}$ & $\begin{array}{l}0^{\circ} \text { Ply } \\
\text { Thickness } \\
(\mathrm{mm})\end{array}$ & $\begin{array}{c}\text { Thickness } \\
\text { Change } \\
(\%)\end{array}$ & $\begin{array}{c}\text { Angle } \\
\theta \\
(\operatorname{deg})\end{array}$ & $\begin{array}{l}\text { CSF }^{1} \\
\text { with } \\
\text { Flaw } \\
(\%)\end{array}$ \\
\hline $\begin{array}{c}\text { (1) ESH: Double interior D } 1550^{\circ} \\
\text { ply drop (RTM) } \\
0^{\circ}: \text { D } 155 \text { Glass Fiber } \\
\pm 45^{\circ}: \text { DB } 120 \\
{\left[0 / 0^{*} / 0^{*} / \pm 45 / 0 /(0 / \pm 45 / 0)_{2}\right]}\end{array}$ & & 2.4 & 35 & 0.55 & -16 & 8 & 1.7 \\
\hline $\begin{array}{c}\text { (2) } 90^{\circ} \text { Material Inclusion } \\
\left(2-90^{\circ} \mathrm{D} 155 \text { plies in center }\right) \\
(\mathrm{RTM}) 0^{\circ}: \text { D } 155 \text { Glass } \pm 45^{\circ} \text { : } \\
\text { DB } 120 \\
\text { DD } 19,\left(0 / \pm 45 / 0 / 90^{*}\right)_{S}\end{array}$ & & 2.4 & \begin{tabular}{|l|}
$34 /$ \\
$47^{3}$
\end{tabular} & 0.56 & $\begin{array}{c}0 \\
(30 \% \text { more } \\
\text { fibers })\end{array}$ & 8 & 1.7 \\
\hline $\begin{array}{c}\text { (3) } 90^{\circ} \text { Material Inclusion } \\
\left(2-90^{\circ} \text { D155 plies in center }\right) \\
(\text { RTM }) 0^{\circ}: \text { A130 Glass } \pm 45^{\circ}: \\
\text { DB } 120 \\
\text { DD19A, }(0 / \pm 45 / 0 / 90 *)_{\mathrm{S}}\end{array}$ & & 1.6 & \begin{tabular}{|l|}
$35 /$ \\
$50^{3}$
\end{tabular} & 0.55 & $\begin{array}{c}0 \\
(37 \% \text { more } \\
\text { fibers })\end{array}$ & 10 & 1.3 \\
\hline $\begin{array}{c}\text { (4) One central } 0^{\circ} \text { ply drop } \\
0^{\circ}: \text { Carbon fiber prepreg } \\
{\left[0_{5}\right] \rightarrow\left[0_{4}\right]}\end{array}$ & & 1.0 to 1.2 & 55 & 0.31 & -20 & 4 & 0.66 \\
\hline $\begin{array}{c}\text { (5) Two central } 0^{\circ} \text { ply drop } \\
0^{\circ}: \text { Carbon fiber prepreg } \\
{\left[0_{6}\right] \rightarrow\left[0_{4}\right]}\end{array}$ & & 1.0 to 1.2 & 55 & 0.31 & -32 & 7 & 0.59 \\
\hline $\begin{array}{l}\text { (6) Central } 6 \mathrm{~mm} \text { long ply joint } \\
\text { gap in two } 0^{\circ} \text { plies } \\
0^{\circ} \text { : Carbon fiber prepreg } \\
\pm 45^{\circ}: \text { dry DB } 120 \\
\left( \pm 45 / 0_{2} / 0_{2} * / 0_{2} / \pm 45\right)\end{array}$ & & 1.0 to 1.2 & 48 & 0.33 & -24 & 16 & 0.34 \\
\hline $\begin{array}{l}\text { (7) Central } 6 \mathrm{~mm} \text { long ply joint } \\
\text { gap in one } 0^{\circ} \text { ply } \\
0^{\circ}: \text { Carbon fiber prepreg } \\
\pm 45^{\circ}: \text { Glass fiber prepreg } \\
\left( \pm 45 / 0_{2} / 0^{*} / 0_{2} / \pm 45\right)\end{array}$ & & 1.0 to 1.2 & 52 & 0.34 & -4 & 7 & 0.55 \\
\hline \multicolumn{8}{|c|}{$\begin{array}{l}\text { * indicates a dropped or jointed ply } \\
{ }^{1} \mathrm{CSF} \text { - Compressive Strain to Failure. }{ }^{2} \mathrm{Angle} \theta \text { is the Maximum Ply Misorientation Angle } \\
\text { Carbon fiber }\left(0^{\circ}\right) \text { prepreg: SE } 4 \mathrm{LV} / \mathrm{SC} 300 \mathrm{C} / 300 / 300 \text { (SP Systems) } \\
\text { Glass fiber }\left( \pm 45^{\circ}\right) \text { prepreg: M } 9.6 / 35 \% / \mathrm{BB} 600 / \mathrm{G} \text { (Hexcel) } \\
\text { Prepreg processing involved a vacuum of } 75 \mathrm{kPa} \text { and an over pressure of } 103 \mathrm{kPa} \text {, except for case } 6 \text {, which used an } \\
\text { over pressure of } 276 \mathrm{kPa} \text {. Prepreg materials were processed with a bag on one side, while RTM cases have a hard } \\
\text { mold on both sides. } \\
{ }^{3} \text { The double entry for the } \mathrm{V}_{\mathrm{F}} \text { gives the average laminate fiber volume fraction away from the inclusion / fiber volume } \\
\text { fraction at the inclusion. }\end{array}$} \\
\hline
\end{tabular}



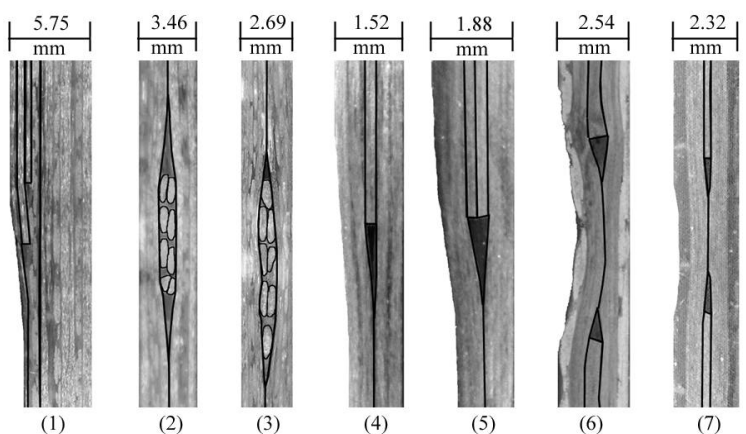

Figure 8. Enhanced Cross-Sectional Views of Thin Glass (1-3) and Carbon (4-7) Laminates Containing Ply Drops, Joints and Inclusions (See Table 2 for details).

Absolute strain values on the order of $0.6 \%$ may produce a significant limitation on the use of carbon in blades. However, ply drops in thick laminates produce less severe effects, as shown later. Fatigue tests have not yet been conducted on the carbon fiber laminates with ply drops and joints. The results given here indicate that a severe loss in compressive strength and ultimate strain are possible with carbon prepreg if care is not taken to avoid the type of distortion evident in Figure 7(6). Lower pressures and single ply drops would reduce the severity of the distortion.

\section{Thick Carbon Laminates with Ply Drops and Joints}

\section{Prepreg Laminates}

Structural areas like spar caps in large wind turbine blades are often several $\mathrm{cm}$ thick, which presents testing challenges when evaluating properties, particularly with flaws like ply drops, which perturb only a small fraction of the thickness. While methodologies are being developed predicting failure in geometries which are prone to delamination [13], it is essential to obtain meaningful test data. For the present study, the effects of ply drops on compressive properties likely depends on the fraction of plies through the thickness which contain ply drops, as well as the location of the ply drop. Here, only one of nine or two of nine $0^{\circ}$ plies were dropped or jointed, a more realistic fraction than for the thin specimens in Figure 8 and Table 2. Test specimens in compression must be symmetrical through the thickness (Figure 5), or have bending and buckling constrained artificially. To provide symmetry, specimens in this study were bonded back-to-back, as noted earlier. This doubles the thickness and the load requirements in testing. Higher loads tend to produce instability in the overall load train as well as in the gage section area. Thus, stiff, high load capacity testing machines are needed.
The maximum failure loads in this study were about $205 \mathrm{kN}$ and several tests series were discarded due to problems with bending and buckling of the coupon or load train. The end loading geometry with large gripped lengths (Figure 5), combined with the $250 \mathrm{kN}$ MTS test system provided adequate stiffness for this series of tests, but thicker specimens may require special test fixturing. Specimens containing ply drops and joints failed at somewhat lower strains, reducing the test problems.

Figure 7 shows several failed specimens containing ply drops and joints. Failures occurred at the site of the dropped or jointed ply, as expected (rare tests which failed at the tab, rather than the ply drop, were not included in the averages). Table 3 gives the test results for a variety of cases. Testing of control specimens with no ply joint or drop provided the gre atest challenge, and test development is continuing. While the average control specimen strain for this test series was $0.86 \%$, tests for thinner specimens (Table 1) gave about $1.0 \%$, and several of the control tests in this series also gave values close to $1 \%$. Since all thick control specimens failed near the tab edge (Figure 7), the thick control results are below what gage-section failures would provide. Taking the control compression failure strain as about $1.0 \%$, the ply joint with no thickness tapering produced a strain reduction to about $0.75 \%$ if the strength is calculated for the overall thickness without considering that one ply is discontinuous. This result would be about $10 \%$ higher if the stress were adjusted to the continuous plies only.

For the cases with a single ply drop, the average failure strains (on the thin end) range from 0.62 to $0.71 \%$. For a double ply drop, they range from 0.44 to $0.55 \%$. The ply drops contain both an exterior shape taper and internal ply misalignment, while the shape effect is eliminated for the ply joint (with a minimal gap). When the ply drop was at the outside $0^{\circ}$ ply, with the exterior $\pm 45^{\circ}$ covering the drop, the ply misalignment angle was minimized, and the average ultimate strain was $0.72 \%$.

While a general correlation of ply misalignment with failure strain is evident in the data, a more detailed analysis of these results will be carried out in future work.

\section{$\underline{\text { Hand Lay-up Laminates }}$}

Thick laminates containing ply drops and joints were also fabricated by hand lay-up. The fabrics were Zoltek UNI25 carbon for the $0^{\circ}$ layers and DB120 glass for the $\pm 45^{\circ}$ layers. The resin was SP Systems Prime 20 epoxy, cured as described earlier. The ply thickness for the 
Zoltek UNI25 is about $1.0 \mathrm{~mm}$ at the fiber volume fraction of 0.50 . Thus, the plies being dropped are about three times thicker than were the prepreg plies. The hand lay-up specimens were molded to the final shape shown in Figure 6, without being bonded back-to-back. Note that the overall fiber volume fraction for these laminates reflects the low fiber content in the $\pm 45^{\circ}$ layers. The insitu fiber volume fraction in the $0^{\circ}$ carbon layers was about 0.46 .

The compression test results are given in Table 4. Test geometry and failure modes were similar to those for prepreg, except that the control material failed in the gage section, while the prepreg failed at the tab (Figure 7).
Thus, the control strength and failure strain are meaningful values for their laminates.

The control compressive strain to failure, $0.78 \%$, was well above that reported earlier for the same carb on fabric with a vinyl ester resin, $0.61 \%$ (Table 1 ). The vinyl ester resin value was obtained for a thinner laminate with no $\pm 45^{\circ}$ layers. The results in Table 4 indicate moderate reductions in compressive strain to failure for all ply drop and joint cases, with similar performance for the two ply drop geometries. These cases out-performed the ply joint case. However, as with the prepreg data, the joint case is deceptive in that the total thickness was used in the stress calculation, while the thin-side cross-sectional area was used for the ply drops.

Table 3. Compression Properties of Thick Prepreg Carbon Hybrid Laminates Containing Ply Drops and Joints (SP Systems SE84LV/HSC/450/400/37\% Carbon/epoxy Prepreg $0^{\circ}$ Plies with Toray T600 Fibers; Hexcel M9.6/35\%/B B600/G Glass/epoxy Prepreg $\pm 45^{\circ}$ Plies; for a Fiber Volume Fraction of 0.50 )

\begin{tabular}{|c|c|c|c|c|c|c|c|c|}
\hline \multirow[t]{2}{*}{ Lay-up } & & \multicolumn{2}{|c|}{$\begin{array}{l}\text { Thickness, } \\
(\mathrm{mm})\end{array}$} & \multirow[t]{2}{*}{$\begin{array}{c}\mathrm{P}_{\mathrm{F}} \\
(\mathrm{kN})\end{array}$} & \multirow[t]{2}{*}{$\begin{array}{l}\mathrm{UCS}^{1} \\
(\mathrm{MPa})\end{array}$} & \multirow[t]{2}{*}{$\begin{array}{c}\mathrm{CSF}^{2} \\
(\%)\end{array}$} & \multirow[t]{2}{*}{$\begin{array}{c}\text { Angle }^{3} \\
(\text { deg })\end{array}$} & \multirow{2}{*}{$\begin{array}{c}\text { Surface } \\
\text { Taper } \\
\text { (deg) }\end{array}$} \\
\hline & & Thick & Thin & & & & & \\
\hline \multirow[t]{2}{*}[\pm45/0_{8}/\mp45]{$_{S}($ control $)$} & avg & ---- & 9.7 & 160 & 765 & 0.86 & 0.0 & 0.0 \\
\hline & std dev & ---- & 0.05 & 25 & 116 & 0.13 & 0.0 & 0.0 \\
\hline \multirow{2}{*}{$\begin{array}{c}{\left[ \pm 45 / 0_{4} / 0 * / 0_{4} / \mp 45\right]} \\
\text { Ply Joint }\end{array}$} & avg & ---- & 5.4 & 83 & 666 & 0.75 & 0.0 & 0.0 \\
\hline & std dev & ---- & 0.1 & 10 & 74 & 0.08 & 0.0 & 0.0 \\
\hline \multirow[t]{2}{*}[\pm45/0*/0_{8}/\mp45]{$_{\mathrm{S}}$} & avg & 11.2 & 10.2 & 151 & 636 & 0.72 & $<2$ & 8.1 \\
\hline & std dev & 0.1 & 0.1 & 5 & 24 & 0.03 & ---- & 1.4 \\
\hline \multirow[t]{2}{*}[\pm45/0/0*/0_{7}/\mp45]{$_{S}$} & avg & 10.9 & 9.9 & 121 & 549 & 0.62 & 6.8 & 5.6 \\
\hline & std dev & 0.07 & 0.1 & 7 & 31 & 0.03 & 1.6 & 2.0 \\
\hline \multirow[t]{2}{*}[\pm45/0_{7}/0*/0/\mp45]{$_{S}$} & avg & 11.0 & 10.2 & 123 & 553 & 0.62 & 6.3 & 4.7 \\
\hline & std dev & 0.1 & 0.07 & 7 & 35 & 0.04 & 1.8 & 1.9 \\
\hline \multirow[t]{2}{*}[\pm45/0_{4}/0*/0_{4}/\mp45]{$_{S}$} & avg & 10.7 & 9.8 & 138 & 633 & 0.71 & 7.9 & 4.9 \\
\hline & std dev & 0.2 & 0.1 & 8 & 37 & 0.04 & 2.3 & 1.1 \\
\hline \multirow[t]{2}{*}[\pm45/0_{3}/0_{2}*/0_{4}/\mp45]{$_{\mathrm{S}}$} & avg & 10.9 & 9.2 & 83 & 387 & 0.44 & 11.5 & 4.7 \\
\hline & std dev & 0.2 & 0.1 & 6 & 32 & 0.04 & 2.6 & 0.5 \\
\hline \multirow[t]{2}{*}[\pm45/0/0_{2}*/0_{6}/\mp45]{$_{S}$} & avg & 11.1 & 9.1 & 101 & 478 & 0.54 & 11.2 & 9.3 \\
\hline & std dev & 0.1 & 0.1 & 5 & 23 & 0.03 & 1.8 & 1.2 \\
\hline \multicolumn{9}{|c|}{$\begin{array}{l}\text { * Indicates a dropped or jointed ply. } \\
1 \text { - Ultimate compressive strength calculated for the thin section. } \\
2 \text { - Compressive strain to failure calculated for the thin section. } \\
3 \text { - Angle is the maximum ply misorientation angle. }\end{array}$} \\
\hline
\end{tabular}


Table 4. Compression Properties of Thick Hand Lay-up Carbon Hybrid Laminates Containing Ply Drops and Joints (Zoltek UNI25 Carbon $0^{\circ}$ fabric with DB $120 \pm 45^{\circ}$ Glass Fabric; Prime 20 epoxy matrix,

fiber volume fraction $=0.38$ )

\begin{tabular}{|c|c|c|c|c|c|c|c|c|}
\hline \multirow[t]{2}{*}{ Lay-up } & & \multicolumn{2}{|c|}{$\begin{array}{l}\text { Thickness, } \\
(\mathrm{mm})\end{array}$} & \multirow[t]{2}{*}{$\begin{array}{c}\mathrm{P}_{\mathrm{F}} \\
(\mathrm{kN})\end{array}$} & \multirow[t]{2}{*}{$\begin{array}{l}\mathrm{UCS}^{1} \\
(\mathrm{MPa})\end{array}$} & \multirow[t]{2}{*}{$\begin{array}{c}\mathrm{CSF}^{2} \\
(\%)\end{array}$} & \multirow[t]{2}{*}{$\begin{array}{c}\text { Angle }^{3} \\
(\mathrm{deg})\end{array}$} & \multirow{2}{*}{$\begin{array}{c}\text { Surface } \\
\text { Taper } \\
(\text { deg) }\end{array}$} \\
\hline & & Thick & Thin & & & & & \\
\hline \multirow[t]{2}{*}[\pm45/0_{7}/\mp45]{$_{S}$ (control) } & avg & ---- & 8.0 & 138 & 630 & 0.78 & 0.0 & 0.0 \\
\hline & std dev & ---- & 0.3 & 10 & 56 & 0.07 & 0.0 & 0.0 \\
\hline \multirow{2}{*}{$\begin{array}{c}{\left[ \pm 45 / 0_{3} / 0^{*} / 0_{3} / \mp 45\right]} \\
\text { Ply Joint }\end{array}$} & avg & ---- & 9.0 & 113 & 468 & 0.58 & 0.0 & 0.0 \\
\hline & std dev & ---- & 0.4 & 14 & 46 & 0.06 & 0.0 & 0.0 \\
\hline \multirow[t]{2}{*}[\pm45/0*/0_{6}/\mp45]{} & avg & 9.6 & 7.6 & 112 & 480 & 0.67 & 3.9 & 11.2 \\
\hline & std dev & 0.3 & 0.1 & 8 & 44 & 0.05 & 0.5 & 1.4 \\
\hline \multirow[t]{2}{*}[\pm45/0_{3}/0^{*}/0_{3}/\mp45]{} & avg & 8.6 & 7.2 & 103 & 554 & 0.69 & 6.1 & 5.1 \\
\hline & std dev & 0.4 & 0.2 & 8 & 39 & 0.05 & 1.1 & 1.4 \\
\hline \multicolumn{9}{|c|}{$\begin{array}{l}\text { * Indicates a dropped or jointed ply. } \\
1 \text { - Ultimate compressive strength calculated for the thin section. } \\
2 \text { - Compressive strain to failure calculated for the thin section. } \\
3 \text { - Angle is the maximum ply misorientation angle. }\end{array}$} \\
\hline
\end{tabular}

Compared with the prepreg results in Table 3, the hand lay-up specimens failed at compressive strains very close to the values for the corresponding single prepreg ply drop geometries. However, the single ply of prepreg is a slightly lower percent of the total number of $0^{\circ}$ plies, and also has a much lower ply thickness. The double ply drop cases with prepreg performed poorly compared with the hand lay-up cases having a single ply drop, but, now, a higher fraction of $0^{\circ}$ plies were dropped for the prepreg laminate.

\section{CONCLUSIONS}

The static compressive strain to failure for large-tow carbon fiber laminates and hybrids is in the range of $1.0 \%$ for prepreg materials which have relatively straight fibers. Carbon fabrics used with infusion processes contain varying amounts of inherent fiber waviness which reduces the failure strain to 0.6 to $0.8 \%$ for average values, not including knockdowns for statistics, environmental effects, or flaws. Epoxy resins produce significantly better results than vinyl ester resins with carbon fibers.

Carbon prepreg laminates containing ply joints and ply drops can have average static compressive ultimate strains as low as 0.3 to $0.5 \%$ for severe cases of wide gaps in ply joints, multiple ply drops at the same location, and cases with a high fraction of $0^{\circ}$ plies dropped at the same location. However, single ply drops and joints can be incorporated in prepreg laminates with static ultimate compressive strains as high as 0.70 to $0.75 \%$. Hand lay-up laminates with woven carbon fabric show very similar compressive strains for corresponding cases; the $0^{\circ}$ ply thickness is greater than for carbon prepreg. All values are for room temperature, dry conditions. The ultimate compressive strains correlate approximately with the ply misalignment angle associated with the ply drop or joint.

\section{REFERENCES}

1. J.F. Mandell and D.D. Samborsky, "MSU/DOE Wind Turbine Blade Composite Material Fatigue Database," February 2002, Sandia National Laboratories, Albuquerque, NM, 87185 .

2. J.F. Mandell, D.D. Samborsky, and D.S. Cairns, "Fatigue of Composite Materials and Substructures for Wind Turbine Blade," Contractor Report SAND2002-077, Sandia National Laboratories, Albuquerque, NM, (2002). 
3. J.F. Mandell, D.D. Samborsky, and L. Wang, Proc. 48th International SAMPE Symposium, L.J. Colen, C.L. Ong, C. Arendt, eds., Vol. 48, SAMPE, Covina, CA, 2003, pp.2653-2666.

4. J.F. Mandell, D.D. Samborsky, L. Wang, and N.K. Wahl, 2003 ASME Wind Energy Symposium, AIAA/ASME, New York, 2003, pp. 167-179.

5. L. Wang, "Effects of In-plane Fiber Waviness on the Properties of Composite Materials," M.S. Thesis, Dept. of Chemical Engineering, Montana State University, (2001).

6. D. Adams, J. Reinforced Plastics and Composites, 12, April 1993, pp. 415-429.

7. D. Adams, and M.W. Hyer, in "Compression Response of Composite Structures, ASTM STP $\underline{1185}$," S.E. Groves and A.L. Highsmith, eds., American Society for Testing and Materials, Phil., 1994, pp.323-337. pp. 65-77.
8. H.M. Hsaio and I.M. Daniel, Composites Sci. and Tech., $\underline{\mathbf{5 6}}$ (1996).

9. K.J. Chun and I.M. Daniel, Composites Sci. and $\underline{\text { Tech., }} \underline{\mathbf{6 1}}$ (2001).

10. E. Barbero, "Introduction to Composite Materials Design," Taylor and Francis, London, (1999) P.89.

11. S. Tan and M. Knight in "Compression Response of Composite Structures, ASTM STP 1185," S.E. Groves and A.L. Highsmith, eds., American Society for Testing and Materials, Phil., 1994, pp.323-337.

12. J.F. Mandell, D.S. Cairns, D.D. Samborsky, R.B. Morehead, and D.H. Haugen, Proc. ASME Wind Energy Symposium, ASME/AIAA, New York, 2003, pp. 200-213. 